\title{
TECNOLOGIAS DIGITAIS MÓVEIS, PRATICANTES DE LÍNGUA INGLESA E CAMINHOS PEDAGÓGICOS PARA O USO DE APPS
}

\author{
MOBILE DIGITAL TECHNOLOGIES, ENGLISH LANGUAGE PRACTITIONERS AND \\ PEDAGOGICAL WAYS FOR USING APPS
}

\section{TECNOLOGÍAS DIGITALES MÓVILES, PRACTICANTES DE HABLA INGLESA Y CAMINOS PEDAGÓGICOS PARA USO DE APLICACIONES}

Luciana de Jesus Lessa Censi ${ }^{1}$

Rosane Meire Vieira de Jesus ${ }^{2}$

\begin{abstract}
RESUMO
Este artigo trata de relações estabelecidas entre tecnologias e aplicativos móveis e os processos de ensinoaprendizagem de língua inglesa por praticantes desse idioma, do $7^{\circ}$ ao $9^{\circ}$ ano do ensino fundamental de uma escola pública. Ao trazer à tona as vozes desses praticantes, objetivou-se entender como se viabiliza outras possibilidades para a educação linguística na cultura digital e cibercultura. Uma vez que os praticantes se caracterizam por desenvolver táticas e criações para subverter situações da realidade que lhes é dada, foram utilizados grupos de diálogo na perspectiva do estudo qualitativo e de uma abordagem interpretativa a partir de Gadamer (1999). Os diálogos evidenciaram implicações em torno do tema e alguns fundamentos que podem orientar caminhos pedagógicos para o uso de aplicativos nos processos de ensinoaprendizagem de inglês, sobretudo, no cotidiano escolar.
\end{abstract}

PALAVRAS-CHAVE: Aplicativos móveis. Praticantes de língua inglesa. Cotidiano escolar.

\section{ABSTRACT}

This article deals with established relationships between technologies and mobile applications and the English teaching-learning processes by practitioners of that language from 7 th to 9 th grades at a public school. By bringing to light the voices of these practitioners, the objective is to understand how other possibilities for

Submetido em: 01/08/2020 - Aceito em: 01/11/2020 - Publicado em: 24/12/2020

${ }^{1}$ Professora efetiva de Língua Inglesa da Rede Estadual de Educação - Bahia; Mestre em Educação pelo Programa de Pós-Graduação em Gestão e Tecnologia Aplicadas à Educação/Universidade do Estado da Bahia (UNEB); Doutoranda do Programa de Pós-Graduação em Língua e Cultura/Universidade Federal da Bahia (UFBA). E-mail: censiluciana@ hotmail.com

${ }^{2}$ Professora Adjunto do Programa de Pós-Graduação em Gestão e Tecnologia Aplicadas à Educação e do Departamento de Educação do Campus XIV/Universidade do Estado da Bahia (UNEB); Doutora em Educação pelo Programa de Pós-Graduação e Pesquisa em Educação/Universidade Federal da Bahia (UFBA). E-mail: rmvieira@uneb.br 
linguistic education in digital culture and cyberculture are feasible. Considering that practitioners are characterized by developing tactics and creations to subvert situations of the reality that are given to them, dialogue groups were used from the perspective of qualitative study and from an interpretative approach based on Gadamer (1999). The dialogues showed implications about the theme and some fundamentals that can guide pedagogical ways for the use of apps in the English teaching-learning processes, above all, in school life.

KEYWORDS: Mobile applications. Practitioners of english. School life.

\section{RESUMEN}

Este artículo aborda las relaciones establecidas entre las tecnologías y aplicaciones móviles y los procesos de enseñanza aprendizaje del idioma inglés por parte de los practicantes de ese idioma, desde el $7^{\circ}$ al $9^{\circ}$ grado de la escuela primaria en una escuela pública. Al plantear las voces de estos practicantes, el objetivo era comprender cómo se hacen posibles otras posibilidades de educación lingüística en cultura digital y cibercultura. Como los practicantes se caracterizan por desarrollar tácticas y creaciones para subvertir las situaciones de la realidad que se les da, los equipos de diálogo se utilizaron en la perspectiva del estudio cualitativo y un enfoque interpretativo de Gadamer (1999). Los diálogos evidenciaron implicaciones en torno al tema y algunos fundamentos que pueden orientar caminos pedagógicos para el uso de aplicaciones en los procesos de enseñanza aprendizaje del inglés, sobre todo, en la rutina escolar.

PALABRAS CLAVE: Aplicaciones móviles. Practicantes de habla inglesa. Cotidiano escolar.

\section{INTRODUÇÃO}

Este texto se refere a um recorte de uma pesquisa de mestrado realizada por uma professora de inglês de uma escola pública com alguns de seus estudantes do ensino fundamental II, cuja problemática envolve as implicações do uso de tecnologias e aplicativos móveis, como o Duolingo, para favorecer o aprendizado do idioma em questão. Buscou-se, então, entender como se viabiliza outras possibilidades para a educação linguística na cultura digital e cibercultura.

Vale ressaltar, à princípio, que para a realização desta pesquisa "com" o cotidiano, o qual é transitório, incontrolável e imprevisível, considerou-se a necessidade de os praticantes do cotidiano trazerem à tona questões pertinentes a eles quanto às ocorrências que vivenciam, tornando-os protagonistas e autores da investigação (FERRAÇO, 2007). Por isso, utiliza-se a expressão praticante de Língua Inglesa (LI) fazendo referência ao estudante, um dos praticantes do cotidiano escolar, a partir das possibilidades de este sujeito construir caminhos próprios para aprenderensinar a LI por meio das táticas e da inventividade (CERTEAU, 1994). 
O cotidiano escolar, em sua multiplicidade e complexidade, em que, muitas vezes, tudo acontece ao mesmo tempo (FERRAÇO, 2007), solicita que não se fragmente ou isole relações entre elementos e/ou processos, haja vista também o risco de o próprio dualismo gerar contradições internas ao conhecimento científico. Logo, 'ensinoaprendizagem' é um termo aqui usado para dar ênfase à inquietação de que o ensino de inglês na escola pode e deve propiciar cada vez mais aprendizagens, mesmo que inúmeras vezes aprendizagens aconteçam sem que haja necessariamente ensino. No mesmo viés, outros termos como aprenderensinar, espaçostempos etc são adotados ao longo do artigo.

Smartphones e outros artefatos digitais estão espalhados por todos os espaçostempos da escola. Consequentemente, são múltiplas as tensões emergentes nesse cotidiano, oriundas da intensificação do digital nas práticas sociais, que têm sido reconfiguradas. Os praticantes estão conectados; fotografam a lousa; tiram selfies e postam imediatamente nas redes sociais; usam o fone de ouvido durante as aulas; e formam grupos durante o intervalo escolar para criar construções no famoso jogo Minecraft ${ }^{3}$. Como praticantes do cotidiano escolar, driblam o sigilo da senha da rede WI-FI da escola e demonstram ser tão apegados aos aparatos tecnológicos que competem no uso das tomadas de eletricidade para carregá-los nas salas de aula.

A vivência e a caracterização desse cotidiano escolar fazem aguçar o nosso interesse em entender os sentidos e significados que esses praticantes constroem a partir das tecnologias digitais móveis, especialmente os celulares, como artefatos técnico-culturais da contemporaneidade. Não tratamos, em momento algum, de abolir ou desvalorizar o livro didático ou qualquer outro material, até porque tudo pode ser material didático, desde que haja uma intenção pedagógica no uso que se faz. No entanto, voltar-se para materiais digitais é uma tentativa de dar atenção a um fenômeno emergente e que pode enriquecer os processos de ensinoaprendizagem de LI a partir do cotidiano escolar.

A cultura digital (CORDEIRO, 2014) está, pois, refletida no acesso que os praticantes de LI têm tido aos dispositivos digitais móveis, nas escolhas que fazem a partir da

\footnotetext{
${ }^{3}$ Trata-se de um jogo eletrônico de sobrevivência em que o jogador explora um mundo aberto tridimensional em blocos, coopera com outros jogadores, combate adversários e adquire recursos para se manter vivo.
} 
portabilidade deles. É a cultura digital que torna possível que esses praticantes de LI sejam também praticantes da cibercultura (SANTOS, 2011), pois quando conectados o acesso a materiais digitais em inglês pode ir além do consumo e resultar em produção, alteração e compartilhamento de conteúdos, experiências de comunicação e de interações.

Com as tecnologias digitais móveis cresce o desenvolvimento de aplicações, aplicativos ou apps. São inúmeros os aplicativos gratuitos que disponibilizam conteúdos e tarefas em LI. As finalidades a que eles se propõem são variadas: vocabulário, gramática, leitura, conversação etc.

Se aprenderensinar inglês através de apps, sobretudo em dispositivos móveis, como smartphones e tablets, tem sido uma oferta cada vez mais frequente, orientamo-nos pela seguinte indagação: a partir da compreensão de compreensões dos praticantes de LI sobre os processos de ensinoaprendizagem desse idioma com o uso de tecnologias e aplicativos móveis, quais são as implicações emergentes e como se fundamentariam caminhos pedagógicos para tal uso? Então, a seguir, o texto trata dos procedimentos metodológicos, caracterizando os participantes e campo de pesquisa, do movimento interpretativo-teórico dos grupos de diálogos e, conseqüentemente, de alguns fundamentos que podem orientar caminhos pedagógicos para o uso de apps, conforme e para o contexto investigado, mas que pode servir de inspiração para outras realidades.

\section{PROCEDIMENTOS METODOLÓGICOS}

Concernente aos praticantes de LI que formaram a amostra da pesquisa, foram 24 praticantes diversos do $7^{\circ}$ ao $9^{\circ}$ ano do ensino fundamental II (todos eles foram alunos de inglês da professora pesquisadora ou de outras disciplinas da área de linguagens), dentre 7 turmas de um colégio público. Filhos de artesão, servente, vendedora, vigilante, técnico em agropecuária e autônomo, todos os praticantes residiam em bairros periféricos da cidade. Ao longo do texto, serão identificados por meio de números em inglês.

Outrossim, todos os praticantes tinham um dispositivo móvel com acesso à rede, já que foi uma condição exigida para a participação na investigação. A maioria utilizou um smartphone durante as atividades propostas, somente um deles apresentou um tablet. Nem 
todos os praticantes tinham o hábito de levar seus dispositivos para a escola. Alguns relataram ter medo de assaltos ou por proibição dos pais ou responsáveis não saíam de casa portando um celular, por exemplo. Entretanto, alguns deles já tinham o costume de levar os smartphones para a escola, sobretudo para fazer uso de jogos, especialmente o jogo Minecraft, citado anteriormente, durante os intervalos e horários vagos em que professores faltavam às aulas.

Quanto ao campo empírico, este se configurou em um colégio localizado na zona urbana que atendia quase duzentos estudantes oriundos de bairros mais distantes do centro, conforme informações no Projeto Político Pedagógico (PPP). O corpo docente era formado por 15 professores. Dois deles concursados para ministrar aulas de LI e possuíam formação na área. As docentes dividiam a carga horária referente às 7 turmas existentes na unidade escolar, sendo 2 hora/aulas ministradas a cada turma semanalmente, e complementavam a carga horária com outras disciplinas.

Ressalta-se que a instituição faz parte do Programa de Educação Integral (ProEI) e oferta educação integral à comunidade, desde 2014 , do $6^{\circ}$ ao $9^{\circ}$ ano do ensino fundamental II. Todos os estudantes permanecem na escola de $7 \mathrm{~h} 20 \mathrm{~min}$ às $15 \mathrm{~h} 40 \mathrm{~min}$.

No laboratório de informática, identificamos 8 computadores inativos e $2 \mathrm{em}$ funcionamento. Há duas redes de internet, $1 \mathrm{MB}$, na escola, cujo acesso legal não é liberado aos praticantes, mas estes, conforme relataram, acabam burlando a regra por meio do uso de apps que descobrem senhas das redes WI-FI e, assim, facilmente a senha é repassada entre eles, possibilitando acessos à internet, mesmo sem qualidade.

Foram organizados encontros entre a pesquisadora e os praticantes de LI. Optamos por chamá-los de grupos de diálogo, pois "compreender uma pergunta quer dizer perguntá-la. Compreender uma opinião quer dizer compreendê-la como resposta a uma pergunta" (GADAMER, 1999, p. 552). Além do que, Gil (2008) salienta características de uma técnica de entrevista em grupo chamada de focus group ou grupo focal, que aparentemente se assemelham às dos grupos de diálogo que realizamos: a moderação do grupo pelo pesquisador, a exposição dos objetivos da pesquisa, das regras de participação e uma questão genérica a ser detalhada até que o moderador perceba que os dados necessários foram obtidos. Todavia, uma característica que marca o grupo de diálogo que criamos é a interação de grupo 
com fins de produzir diálogos que alterem os horizontes dos envolvidos e promovam práticas alternativas para a realidade investigada. O grupo de diálogo é uma tentativa de compreensão não dos indivíduos pesquisados, mas de junto com eles compreender implicações do fenômeno estudado e propor a (re)construção de práticas.

Foram realizados 3 grupos de diálogos (GD) com os praticantes de LI, na escola, no decorrer do trabalho de campo, no último trimestre de 2016, em horários diferentes das aulas com a professora pesquisadora. Cada um deles teve duração de 20 a 30 minutos. Foram utilizados um caderno de campo e um gravador de áudio para os registros.

Entretanto também aproveitamos instantes de espontaneidade dos praticantes. Nas nossas aulas os observamos, sobretudo, a partir das relações que estabelecem com a LI, as tecnologias e aplicativos móveis; andamos pela escola durante alguns intervalos e tomamos notas de campo do que julgamos pertinente ao estudo. Verificou-se, para este estudo, uma grande vantagem da técnica de observação participante natural, na qual há a participação real do observador na vida da comunidade da qual já faz parte, pois, além de poder captar esclarecimentos que acompanham o comportamento dos observados (GIL, 2008), relacionamos e traçamos paralelos entre os enunciados dos praticantes nos grupos de diálogos - mais adiante explicitados - e seus comportamentos no cotidiano escolar.

Partindo de apps que já eram conhecidos por alguns, nos grupos de diálogo, os praticantes de LI discutiram quanto às possibilidades para o uso de apps para aprenderensinar LI, a partir das expectativas deles. Como são as suas aulas de inglês? O que te interessa aprender em inglês? Como você gostaria de usar tecnologias digitais móveis e em rede nas aulas de inglês? Tais questões foram feitas para gerar interações entre os praticantes de LI. Porém, no presente texto, daremos enfoque à avaliação livre do aplicativo móvel Duolingo pelos praticantes de inglês e aos rastros e pistas identificados durante os grupos para fundamentos que podem orientar caminhos pedagógicos no que tange ao uso de apps.

\section{MOVIMENTO INTERPRETATIVO-TEÓRICO DOS GRUPOS DE DIÁLOGO}


É notório que o fenômeno de proliferação de aplicações de softwares móveis tem se tornado cada vez mais emergente. O GD 1 foi iniciado na tentativa de experimentar o aplicativo Duolingo (a seguir explicitado), principalmente porque muitos dos praticantes não o conheciam. Porém, uma vez que o app, escolhido pelos praticantes, só pode ser usado online, logo se impôs o desafio da rede de internet WI-FI, uma vez que a conexão se mostrava lenta. Mediante a situação, foi solicitado que os praticantes pudessem explorar o Duolingo em casa, já que todos afirmaram ter internet em casa, para que, no encontro seguinte, pudessem compartilhar as experiências, pontos positivos e negativos percebidos no app para se aprenderensinar inglês.

O reagendamento do GD 1, por conta da falta de qualidade da banda larga disponível na escola, mostra a necessária urgência de programas governamentais que, de fato, concretizem a implementação de banda larga de qualidade para atender a demanda existente na escola pública e para que se alcance desfechos exitosos, bem diferentes dos que encontramos e faremos menção.

Ao buscarmos pesquisas que abordem a questão das políticas públicas educacionais quanto às tecnologias digitais móveis e redes sem fio nas escolas, o histórico que encontramos não é grandemente positivo. Cordeiro (2014) relata o fracasso do Proinfo, criado em 1997 e reformulado em 2007 com a nomenclatura Programa Nacional de Tecnologia Educacional, que foi responsável pela implantação de laboratórios de informática, dos Núcleos de Tecnologia Educacional (NTEs) e Núcleos de Tecnologia Municipal (NTMs). Contudo, sem a infraestrutura adequada para os laboratórios, software proprietário e formação superficial para os professores, logo as dificuldades resultaram na descontinuidade do programa nas escolas.

De igual forma, Cordeiro (2014) expõe sobre os investimentos do governo em programas e projetos voltados para as tecnologias digitais móveis e software livre a partir de 2007, como UCA, Prouca e tablets na escola. Estes, por sua vez, fracassaram por motivos semelhantes, pois também se assentavam em uma concepção instrumentalizante quanto ao uso das tecnologias. O Projeto Um Computador por Aluno (UCA) foi implantado com o objetivo de intensificar as tecnologias da informação e da comunicação (TIC) nas escolas, por meio da distribuição de computadores portáteis aos alunos da rede pública de ensino, em 
2005, segundo declaração na página eletrônica do Fundo Nacional de Desenvolvimento da Educação (FNDE).

Segundo Fantin e Quartiero (2015), o projeto UCA contou com três fases: pré-piloto (2007), com o recebimento de laptops por cinco escolas; piloto (2009), com a distribuição de laptops para uma média de quatrocentas escolas; e a última (2010), quando o Programa UCA/PROUCA foi ampliado por meio de um decreto presidencial que articulava o financiamento para a compra de laptops por Prefeituras ou Estados interessados por meio do Banco Nacional de Desenvolvimento Econômico e Social (BNDES).

Quanto à entrega de tablets para professores do ensino médio, o Ministério de Educação (MEC) reconhece, em página eletrônica oficial, a ação como parte do Proinfo Integrado, programa de formação voltada para o uso didático-pedagógico das Tecnologias da Informação e Comunicação (TIC) no cotidiano escolar, articulado à distribuição dos equipamentos tecnológicos nas escolas e à oferta de conteúdos e recursos multimídia e digitais. Primeiramente, os tablets foram distribuídos somente para os professores do ensino médio cuja escola fosse urbana, tivesse internet banda larga, laboratório do Programa Nacional de Tecnologia Educacional (ProInfo) e rede sem fio (WI-FI). O governo prometeu que, na segunda fase, os tablets seriam direcionados aos professores das séries iniciais do ensino fundamental, o que não se concretizou.

Teles, Oliveira e Barone (2014, p. 169) apontaram a menção feita pelo Plano Nacional de Educação (PNE 2011-2020) ao uso de tecnologias na escola. Eles dão destaque para as metas 7 e 9 do documento, as quais têm como focos, respectivamente, a melhoria da qualidade da educação básica em todas etapas e modalidades e o solucionamento dos analfabetismos absoluto e funcional. Para tanto, entre as estratégias delineadas, aparecem:

7.14) Universalizar, até o quinto ano de vigência deste PNE, o acesso à rede mundial de computadores em banda larga de alta velocidade, e triplicar, até o final da década, a relação computadores/aluno(a) nas escolas da rede pública de educação básica, promovendo a utilização pedagógica das tecnologias da informação e da comunicação.

[...]

[...] 9.11) Implementar programas de capacitação tecnológica da população jovem e adulta, direcionados para os segmentos com baixos níveis de escolarização formal e alunos(as) com deficiência, articulando sistemas de ensino, a rede federal de educação profissional e tecnológica, universidades, cooperativas e associações, por 
meio de ações de extensão desenvolvidas em centros vocacionais tecnológicos, com tecnologias assistivas que favoreçam a efetiva inclusão social e produtiva dessa população (BRASIL, 2011).

Logo, existe de fato o reconhecimento legal de que é necessário que se promova o acesso às tecnologias digitais móveis e em rede nas escolas, que a cultura digital e a cibercultura adentrem à cultura escolar. Mas os programas e projetos voltados ao uso de tecnologias digitais em educação não têm alavancado. Na própria escola que constitui o campo dessa pesquisa, a sala onde se encontra em torno de 10 computadores desktops está inutilizada. Por falta de manutenção, muitas máquinas já nem funcionam. Talvez o cerne do problema seja mesmo o "[...] distanciamento entre a infraestrutura, disponibilidade em quantidade de máquinas, condições de acesso e capacitação de recursos humanos para um atendimento eficaz do aluno aprendiz", como preconiza o PNE (TELES; OLIVEIRA; BARONE, 2014, p. 171).

Vive-se em tempos que solicitam inclusão digital e cibercultural (SANTOS, 2011) por parte da escola. A criação de políticas para a aprendizagem móvel, por si só, não garante e não tem garantido a inclusão da tecnologia móvel em rede nas salas de aula. A efetivação de projetos e políticas está relacionada a diversos fatores, como a fragilidade na formação dos professores e no uso do computador (e outras tecnologias) como uma máquina pedagógica (BONILLA; PRETTO, 2015). Portanto, quanto às ações governamentais para a implementação de tecnologias digitais na educação, ocorreram medidas esporádicas que não são constituintes de um plano continuado para integrar essas tecnologias de forma responsável, bem estruturada e eficiente às práticas escolares.

Durante a fase de escolha do primeiro aplicativo a ser avaliado, já se percebeu, por parte dos praticantes de LI, esclarecimentos bem definidos que caracterizam seus interesses e objetivos concernentes a aprender inglês em apps. Desenvolver fluência e aprender a se comunicar oralmente no idioma são atrativos a alguns praticantes no Duolingo.

Pesquisadora - Como você daria aulas de inglês pra alguém?

Praticante two - Não sei, pró. Eu receitaria um aplicativo.

Pesquisadora - Qual aplicativo?

Praticante two - O Duolingo que é o que eu uso. Ele é o melhor.

Pesquisadora - Fala aí sua experiência com o Duolingo.

Praticante two - Acho que tirando a escola, foi o que eu mais aprendi, foi nele. 
Praticante eight - Já deu 5 estrelas?

Praticante two - Não, mas estou $36 \%$ fluente em inglês. Na verdade, eu tava procurando aplicativo para falar inglês, aí foi que eu achei ele. Na verdade, eu baixei ele pra testar.

Pesquisadora - O que você faz no Duolingo?

Praticante two - Ele faz as perguntas e eu respondo. Se a gente errar ele vai e passa pra outra pergunta. Aí depois, vai no final, aparece a mesma pergunta.

Pesquisadora - Você usa todo dia?

Praticante two - Hunrum, tem que usar 5 vezes por dia.

Praticante fifteen - Mas se quiser pode usar mais...(GD 1)

Leffa (2016b) considera o Duolingo como um site híbrido, que integra características de rede social, jogo virtual e site educacional. Na página eletrônica, o convite para o "ensino personalizado" é o que antemão se destaca como título. O praticante two, ao se referir a sua fluência e a quantidade de vezes em que usa o app diariamente, remete ao ensino personalizado prometido pelo Duolingo, quando progressos individuais são reportados e a frequência de uso se dá conforme os objetivos de cada um. A autocorreção também se destaca na fala supracitada pelo praticante $t w o$.

O diálogo anterior acabou desencadeando outros pontos de vista dos praticantes de LI sobre o aplicativo Duolingo. Mesmo aqueles que não tinham usado o app ainda, de alguma forma já tinham ouvido falar dele e acabaram tecendo comentários.

Praticante nineteen - Eu já usei, porque na verdade, o Duolingo faz perguntas em inglês, que você tem que entender o que ele falou e você também vê em português pra responder em inglês. É como uma conversa.

Praticante one - Bom que você adquire a prática de conversação.

Praticante fifteen - Tem áudio também, tem horas que você tem que falar a frase...

Praticante nineteen - Tem uma que você tem que conhecer o áudio em inglês e digitar em português. (GD 1)

As atividades do Duolingo que são mencionadas pelos praticantes têm ênfase na tradução de palavras, de frases e na repetição oral. Por isso Leffa (2016b) entende que, do ponto de vista pedagógico, o Duolingo ensina línguas como antigamente ao enfatizar a tradução de frases descontextualizadas. Outros pesquisadores sinalizam o mesmo ponto de vista.

Duolingo, por exemplo, é um site de ensino de idiomas gratuito, que utiliza uma plataforma crowdsourcing de tradução de textos. Ou seja, trata-se de uma plataforma que convida internautas a aprender idiomas enquanto traduzem conteúdos da web (GOMES, ARAÚJO e LOPES, 2014, p. 311). 
Ainda assim, no Duolingo, por constar trechos de áudio, mesmo que sejam para repetir ou traduzir, entende-se que os praticantes encararam essas tarefas como práticas de conversação: "Deixa eu ver... deu pra aprender várias palavras novas, aprender a pronúncia das palavras em inglês, conversar" (Praticante fifteen, GD 1).

Como praticantes da cibercultura (SANTOS, 2011), nos enunciados logo abaixo, os praticantes de LI externaram condições para a autoria, haja vista os conhecimentos e interesses que expuseram sobre como seria um aplicativo para atender suas necessidades. Também reforçam a importância de a língua ser apresentada em modalidades diferentes e explorando dimensões variadas da linguagem.

Praticante nineteen - Que tal um app desse que seja offline?

Praticante six - Não tem... se tivesse um app que você não tivesse de usar internet, o app ia ser pesado porque tem um monte de palavras...

Praticante eight - Quem vai querer um dicionário de 1 giga... eu já não quero mais.

Praticante eighteen - Mas assim você pegar uma imagem e áudio ajudam muito... quando você olha uma imagem seu cérebro grava aquilo, já tá tendo uma ideia. E a audição também ajuda muito na hora de você aprender a gravar aquilo. Tipo, não é só escrever, não é só visualizar, mas também tem que escutar.

Praticante six - Vai ter que ter a áudio pra pessoa aprender a pronunciar. (GD 1)

Embora, no início dos grupos de diálogo, os praticantes de LI tenham criticado as atividades extremamente escritas nas aulas de inglês, no Duolingo foi quase unânime expressar o gosto pelas atividades de tradução, provenientes também de métodos tradicionais de ensino de línguas.

Talvez maior do que o gosto pelas atividades de tradução seja o prazer do jogo despertado por um clima de competição entre os usuários, já que é possível seguir os amigos e ter acesso ao progresso deles, comparando o número de pontos obtidos nas lições. Alguns participantes usavam o Duolingo no momento em que o GD 1 acontecia e pareciam desafiar presencialmente uns aos outros na realização das tarefas no app.

Pesquisadora - Quais foram as partes que você mais gostou do aplicativo?

Praticante fifteen - A parte que dá pra gente... que traduz.

Praticante twenty-one - Eu gostei desse aplicativo porque também pelo fato dele ser tipo um game que tem fases...

Praticante six - Gostei da interface. A interface é interessante.

Praticante seventeen - Eu ia falar isso, roubou minha fala. 
Praticante twenty-two - Eu gostei. Eu achei que parece um jogo, ele ensina melhor o inglês e a gente aprende melhor. Gostei de descobrir frases. Assim, no caso, ele botou pra gente descobrir frases em inglês. Teria que botar em português, falar em português ou algum que saí em português e a gente tem que falar em inglês.

Praticante twenty-three - Eu achei interessante por causa que ele parece um jogo, tem imagens e ele também pode falar, ele repete a frase e a gente tem que repetir né pra aprender. Eu aprendi muitas coisas e tem várias lições pra fazer e é isso.

Praticante twenty-two - Eu gostei muito, muito do aplicativo. Professora, eu vou desinstalar todos os jogos do meu celular só pra instalar esse aplicativo.

Praticante one - Eu vi pela interface dele tem nível básico, depois vai pro inglês mais fluente, depois, depois você vai, acho... pelo que eu vi ali, no último nível você já tá sabendo manejar a escrita ou a pronúncia. Bem legal o aplicativo. (GD 1)

Além da valorização da tradução, que, na verdade, é o tipo de atividade que mais aparece no app, os praticantes ressaltaram questões sobre a semelhança do aplicativo com um jogo, apresentando etapas que vão promovendo o usuário a um nível mais avançado no curso. A interface atrativa também segue os moldes de um jogo dividido em fases. Algumas outras características do Duolingo servem mesmo para produzir um clima de jogo: pontuação ao final das lições que remetem ao aumento ou diminuição da fluência do usuário, ganho de moedas a depender dos resultados que podem ser trocadas por bônus, bloqueio de ofensiva etc. Sem a prática, o desenvolvimento do usuário cai. A porcentagem de fluência também diminui, subentendendo que quanto mais você pratica, mais fluente você fica.

Verificou-se que, por apresentar uma interface gráfica intuitiva, até mesmo os praticantes de LI que não realizaram atividades, mas que somente entraram na plataforma, puderam socializar opiniões sobre o app, ainda expressando motivação para usá-lo em ocasiões posteriores.

A impressão de que se está aprendendoensinando uma língua através de um jogo interessante tem relação direta com o uso de games na educação, sobre o que pesquisadores já têm se debruçado (ALVES, 2008; KAPP, 2012; SQUIRE, 2011). A proposta de gamificação na educação, que antes era usada no meio corporativo para motivar e fidelizar clientes (LEFFA, 2014), tem ganhado espaço a ponto de o Ministério da Cultura (MinC) reconhecer os games como um produto audiovisual, além do Ministério da Educação (MEC) apoiar o desenvolvimento de ambientes gamificados, como o Geekie games - denominada plataforma oficial da Hora do ENEM, na qual praticantes podem experimentar o aprendizado adaptativo 
através de desafios para lhes auxiliar na preparação para o Exame Nacional do Ensino Médio (ENEM) (ALVES; MINHO; DINIZ, 2014).

Portanto, pode-se dizer que a gamificação é um aspecto preponderante no Duolingo. Os praticantes de LI só atestaram o que pesquisadores já anunciaram: “ele [o Duolingo] é, em termos de design, um exemplo de sucesso de gamificação na área de ensino de línguas" (LEFFA, 2014, p. 1).

O Duolingo parece concentrar-se mais nos aspectos do jogo para aprenderensinar do que na maneira como a língua é apresentada. A questão da língua em sua forma tradicional é considerada por Leffa (2016b) ao apontar que o Duolingo fragmenta a língua, utiliza o mesmo corpus para diferentes línguas. A gamificação é realmente tão intensa no app em detrimento às expectativas de desenvolvimento da competência comunicativa que os praticantes de LI não se incomodaram com a ênfase na tradução de frases descontextualizadas.

Ao discutir sobre os aplicativos móveis já instalados e mais usados nos dispositivos dos praticantes, os relatos foram variados:

Praticante nine - $\mathrm{O}$ messenger, a netflix, o facebook e o youtube.

Praticante twenty-one - Eu tenho o facebook, o messenger, whatsapp.

Praticante sixteen - Youtube, whatsapp e dramafever.

Praticante twenty-four - Facebook e whatsapp.

Praticante fifteen - Instagram, Snapchat.

Praticante nineteen - Eu tenho um aplicativo chamado giganima, que é de assistir animes também.

Praticante eighteen - Netflix, youtube.

Praticante seventeen - Eu uso messenger, soundcloud, animesorion, animesFox e superanimes.

Praticante six - Eu uso powerdirector e picsArt.

Praticante twenty-three - Snaptube. Pra baixar filmes e músicas.

Praticante twenty-four - Eu uso kpop amino. É para você conversar sobre músicas, bandas, grupos.

Praticante seven - Eu tenho duolingo e o snaptube. (GD 3)

Aplicativos móveis, então, são explorados pelos praticantes de LI, sobretudo para comunicação, interação e entretenimento: assistir filmes e animes, bater papo, fazer chamadas, assistir vídeos, editar vídeos, ouvir músicas, editar e enviar imagens, acessar sites de redes sociais, baixar vídeos, filmes e músicas, estudar línguas, acessar comunidade de música pop coreana (K-pop), e criar slideshow com fotografia e música. 
$\mathrm{Na}$ verdade, as aplicações nos celulares tendem a facilitar "práticas sociais que emergem dessa mobilidade informacional digital" (LEMOS, 2010, p. 162). Outrossim, em muitas práticas nos apps relacionados, são confirmados rastros de autoria em rede, pois "com a Web 2.0, passamos a ter conteúdos criados, publicados e editados pelos próprios praticantes da rede." (SANTOS, 2011, p. 84). O contato com línguas estrangeiras, como o coreano, é também salientado, evidenciando que idiomas, além do inglês, têm feito parte dos cotidianos desses praticantes.

Falando mais especificamente sobre as possibilidades de uso dos aplicativos móveis em inglês, os praticantes destacaram o benefício dos apps para o desenvolvimento de habilidades comunicativas. Além disso, o fator monetário foi também lembrado, considerando que muitos apps são encontrados gratuitamente na rede.

Praticante one - Como o Google tradutor ajuda na escrita do inglês, tem aplicativos que ajudam na sua pronúncia, praticamente tudo pode melhorar. E é mais barato... que os aplicativos são de graça.

Praticante seventen - É porque tem muitos aplicativos que são de graça, e você não precisa pagar. Tem professores que você tem que pagar a aula.

Praticante twenty-four - Eu acho que os aplicativos, Duolingo, são muito úteis porque tem gente que paga curso para inglês, sendo que tem o Duolingo para ajudar. (GD 3)

A questão da mobilidade também foi citada por um dos praticantes como uma vantagem para o uso de apps para aprender LI: "Um aplicativo tecnológico, você pode levar ele para qualquer lugar, seja pc ou celular, tablet e fica até mais fácil. Você não precisa comprar equipamento" (Praticante nineteen, GD 3). Talvez a vantagem apontada seja uma alternativa diante da insuficiência e/ou ausência de políticas públicas no contexto das tecnologias em educação.

Se por um lado os praticantes expressam credibilidade para aprenderensinar inglês através de apps, pelo outro, demonstram valorização ao professor comparado aos apps: "O básico [referindo-se a aprenderensinar inglês pelo app]. Não é aquele, ah, que grande professor" (Praticante seventeen, GD 3). Os aplicativos móveis parecem se apresentar aos praticantes de LI não como substitutos dos professores, mas como aliados, complementos que priorizem, acima de tudo, a interação e o desenvolvimento de habilidades linguísticas que 


\section{Revista Docência e Cibercultura}

extrapolem a leitura, além de os capacitarem para interagir com outros indivíduos em culturas e cotidianos diversos.

A valorização do professor, no quadro em que crescem as relações entre as pessoas por meio da linguagem, é de grande relevância, pois nunca foi tão necessário aprenderensinar línguas estrangeiras (LEFFA, 2016a, p. 141). Os praticantes reconhecem o lugar dos docentes. Resta aos docentes buscarem entender seu novo papel no estilo de pedagogia em que não se transmite conhecimentos, desperta-se, mobiliza-se a construção deles.

\section{ALGUNS FUNDAMENTOS PARA CAMINHOS PEDAGÓgICOS NO USO DE APLICATIVOS MÓVEIS NOS PROCESSOS DE ENSINOAPRENDIZAGEM DE LI}

À primeira instância, enfatiza-se que os fundamentos foram elaborados a partir dos rastros ou pistas que os praticantes de LI do $7^{\circ}$ ao $9^{\circ}$ ano forneceram. Tais informações emergiram durante as observações do cotidiano escolar e a realização dos grupos de diálogos.

Colocaram-se em evidência os seguintes fundamentos: ensinoaprendizagem das quatro habilidades comunicativas, aspectos relacionados à inclusão na cibercultura, como exploração de dimensões diferentes da linguagem a partir da convergência de mídias, conectividade com o ciberespaço, autoria em rede, interações e promoção de redes sociais na rede, incentivo a inteligências coletivas, aprendizagens coletivas em rede, e, por último, gamificação.

Assim como Leffa (2016a) e Schmitz (2009) apontaram ser imprescindível um trabalho com as quatro habilidades comunicativas: reading, writing, speaking e listening ${ }^{4}$ nos processos de ensinoaprendizagem de inglês, os praticantes de LI, por sua vez, manifestaram extremo desejo de experienciar o idioma em modalidades que não se restrinjam apenas à leitura e à escrita, mas os capacite a atuar em diferentes eventos de comunicação.

A exploração de dimensões diversas da linguagem ampara-se no uso dos próprios dispositivos digitais móveis dos praticantes, uma vez que eles oferecem novas funções

\footnotetext{
${ }^{4}$ Leitura, escrita, fala e compreensão auditiva [tradução nossa].
} 
midiáticas e, consequentemente, possibilitam a ocorrência de novas práticas para aprenderensinar línguas. Assim, facilita-se o aproveitamento de dimensões como a sonora, a imagética, a textual etc. Santos (2011, p. 91-92) esclarece sobre o potencial da convergência de mídias:

A convergência também não é uma noção exclusiva da cibercultura. Se analisarmos do ponto de vista da linguagem, podemos situar os meios impressos como seus primeiros exemplos. Num texto de jornal já contamos com uma infinidade de linguagens (textos, imagens, gráficos) numa mesma interface. Os meios audiovisuais avançam para a integração de textos, imagens e sons num mesmo suporte, a exemplo do cinema e da TV. Por outro lado, é na cibercultura que chegamos ao ápice da convergência de mídias. O celular ou os tablets mais atuais integram num mesmo suporte diversas mídias (câmera fotográfica, filmadora, gravador de som, web com suas interfaces e redes sociais) e estas com o ciberespaço.

O potencial existente na tecnologia móvel conectada se mostra como um aliado às práticas de ensinoaprendizagem de LI mais autênticas e interativas. São possibilidades que podem enriquecer as aulas de línguas e atender às perspectivas expostas pelos praticantes de LI.

Considerando-se que a cibercultura (CORDEIRO, 2014) diz respeito ao que emerge a partir da conectividade e das ações em rede, a possibilidade de criar e de compartilhar conteúdos em rede reverbera-se na ideia de produção de aplicativos, uma vez que os praticantes de LI e da cibercultura planejam ou já realizam ações autorais em rede, como a criação de canais no Youtube.

Estar conectado na escola ou ter acesso à rede pode ser para os praticantes de LI e da cibercultura uma oportunidade não somente de propagar autorias, mas de tecer e construir conhecimentos de maneira coletiva. Nesse contexto, inteligências coletivas, aprendizagens personalizadas e aprendizagem coletiva em rede podem ser estimuladas e intensificadas (LÉVY, 1999). A disponibilidade de materiais digitais gratuitos em rede torna possível, por exemplo, o acesso a aplicativos que podem, com intencionalidade pedagógica, incentivar as referidas inteligências e aprendizagens.

Visto que o ciberespaço, em tempos de cibercultura e de redes sociais, é um lugar multirreferencial de aprendizagem no qual acontece a interatividade com culturas, linguagens, discursos etc. (SANTOS, 2011), dá-se destaque a interações e à promoção de redes sociais na 


\section{Revista Docência e Cibercultura}

rede, dialogando com a concepção de que "rede social na internet parte da ideia de conectar praticantes com interesses comuns que interagem colaborativamente a partir da mediação sociotécnica e de suas conexões." (SANTOS, 2010 apud SANTOS, 2011, p. 84-85). Conforme seus discursos, os praticantes de LI já estão a tecer redes sociais na rede, bem como são usuários de softwares de redes sociais: Youtube, Twitter e Facebook (FB), por exemplo.

Por meio de interações e promoção de redes sociais na rede, em meio ao fenômeno de cibercultura, é possível vislumbrar potencialidades pedagógicas emergentes. Daí, voltam-se às ideias de inteligências coletivas e aprendizagem coletiva em rede (LÉVY, 1999) e sugerese o uso de aplicativos que ofereçam possibilidades de interação e de contato entre os praticantes de LI e quaisquer outros interessados em aprenderensinar LI. No Duolingo, a propósito, existem espaços reservados para diálogos entre os usuários dos cursos. É possível que se adicione amigos para um acompanhamento de progresso nas lições, assim como participar de clubes para interações e compartilhamento de progresso com usuários desconhecidos.

O fundamento que ocupa maior destaque para os caminhos pedagógicos chama-se, sem dúvidas, gamificação. Confirmando o que anunciam Alves (2010), Leffa (2014), Alves, Minho e Diniz (2014), Busarello, Ulbricht e Fadel (2014) sobre gamificação, vê-se, no convívio com os praticantes, a empolgação em torno da experiência de aprenderensinar uma língua em um aplicativo e, ao mesmo tempo, parecer estar num jogo em que se passa por fases e se alcança metas. As lições no app Duolingo, por exemplo, são disponibilizadas à medida que o usuário avança nos resultados e cumpre as metas.

Por fim, muito mais do que recomendar usos de tecnologias e aplicativos móveis para os contextos de ensinoaprendizagem de LI no cotidiano escolar, os fundamentos apresentados implicam em despertar a atenção para os processos emergentes a partir dos novos artefatos técnico-culturais. Talvez o primeiro êxito a ser conquistado não seja relativo a aprenderensinar inglês, mas a aprenderensinar que a cibercultura está aí a fim de possibilitar novas formas e práticas coletivas em rede para aprenderensinar inglês e quaisquer outros saberes. 


\section{CONSIDERAÇÕES FINAIS}

Não encerramos trazendo alguns fundamentos para caminhos pedagógicos no uso de apps que transformarão, em curto prazo, os processos de ensinoaprendizagem de LI dentrofora dos espaçostempos da escola, mas sinalizamos a necessidade de os processos pedagógicos considerarem o universo múltiplo e real dos praticantes de LI, seus interesses, competências e práticas sociais. Espera-se, dessa maneira, contribuir para a educação em línguas e com discussões de tecnologias e linguagens, a partir das significações que elencamos.

Será possível que os praticantes de LI acrescentem à lista de aplicativos que já usam um app para aprenderensinar inglês? Os apps em inglês atendem aos interesses dos praticantes? Eles podem ser integrados às práticas de língua no cotidiano escolar como materiais complementares? Talvez a investigação realizada não tenha condições de responder objetivamente a essas questões, mas a tarefa realizada foi a de escutar, dar ouvidos aos barulhos de alguns praticantes de LI no que concerne às demandas de ensinoaprendizagem dessa língua frente às tecnologias digitais móveis e aos aplicativos.

\section{Referências}

ALVES, Lynn Rosalina Gama. Relações entre os jogos digitais e aprendizagem: delineando percurso. Educação, Formação \& Tecnologias, v. 1, n. 2, p. 3-10, novembro 2008. Disponível em: <http://eft.educom.pt/index.php/eft/article/view/58>. Acesso em: 30 jul. 2019.

ALVES, Lynn Rosalina Gama. Jogos, educação e história: novas possibilidades para Geração C. Plurais: Revista Multidisciplinar da UNEB, Salvador, v. 1, n. 2, p. 209-225, maio/ago. 2010.

ALVES, Lynn Rosalina Gama; MINHO, Marcelle Rose da Silva; DINIZ, Marcelo Vera Cruz. Gamificação: diálogos com a educação. In: FADEL, Luciane Maria et al. (Org.).

Gamificação na educação. São Paulo: Pimenta Cultural, 2014. p. 74-97.

BUSARELLO, Raul Inácio; ULBRICHT, Vania Ribas; FADEL, Luciane Maria. A Gamificação e a Sistemática de Jogo: conceitos sobre a gamificação como recurso motivacional. In: FADEL, Luciane Maria et al. (Org.). Gamificação na educação. São Paulo: Pimenta Cultural, 2014. p. 11-37. 
CERTEAU, Michel de. A invenção do cotidiano: 1. Artes de fazer. Tradução de Ephraim Ferreira Alves. Petrópolis: Vozes, 1994.

CORDEIRO, Salete de Fátima Noro. Tecnologias digitais móveis e cotidiano escolar: espaços/tempos e aprender. 2014. 322 f. Tese (Doutorado em Educação) - Faculdade de Educação. Universidade Federal da Bahia, Salvador. 2014. Disponível em: <https://repositorio.ufba.br/ri/handle/ri/17729>. Acesso em: 25 jul. 2019.

DUOLINGO: por que o Google investe na máquina que ensina? Revista Veja, 3 out. 2015. Disponível em: <http://veja.abril.com.br/tecnologia/duolingo-por-que-o-google-investe-namaquina-que-ensina/>. Acesso em: 27 mar. 2017.

FERRAÇO, Carlos Eduardo. Pesquisa com o cotidiano. In:.Educação \& Sociedade Dossiê: "Cotidiano Escolar" Campinas, v. 28, n. 98, jan./abr. 2007. Disponível em: $<$ http://www.scielo.br/scielo.php?script=sci_arttext\&pid=S0101$73302007000100005 \& \operatorname{lng}=$ pt $>$. Acesso em 22 jan. 2017.

GADAMER, Hans-Georg. Verdade e método I: traços fundamentais de uma hermenêutica filosófica. Tradução de Flávio Paulo Meurer. 3. ed. Petrópolis: Vozes, 1999. GEE, James Paul. Learning by design: games as learning machines. Interactive Educational Multimedia, [s.1.], n. 8, p. 15-23, abr. 2004.

GIL, Antônio Carlos. Métodos e técnicas de pesquisa social. São Paulo: Atlas, 2008.

GOMES, Nelson; ARAÚJO, Silvia; LOPES, Sérgio. Aplicações Móveis: uma ferramenta para aprendizagem de línguas. In: COLÓQUIO DE OUTONO. 15., 2014, Ribeirão - V.N. Famalicão. As humanidades e as ciências: disjunções e confluências. Ribeirão - V.N. Famalicão: Edições Húmus; Universidade do Minho/Centro de Estudos Humanísticos, 2014. p. 305-322. Organização de Ana Gabriela Macedo, Carlos Mendes de Sousa e Vítor Moura.

KAPP, Karl M. The gamification of learning and instruction: game-based methods and strategies for training and education. San Francisco, CA: Pfeiffer \& Company, 2012.

LEFFA, Vilson. Gamificação adaptativa para o ensino de línguas. In: CONGRESSO IBERO AMERICANO DE CIÊNCIA, TECNOLOGIA, INOVAÇÃO E EDUCAÇÃO. 2014, Buenos Aires. Anais... Buenos Aires: OEI, 2015, p. 1-12.

LEFFA, Vilson.Língua estrangeira: ensino e aprendizagem. Pelotas: Educat, 2016a.

LEFFA, Vilson. Redes sociais: ensinando línguas como antigamente. In: ARAÚJO, Júlio; LEFFA, Vilson (Org.). Redes sociais e ensino de línguas: o que temos a aprender? São Paulo: Parábola Editorial, 2016b. p. 49-64. 
LEMOS, André. Celulares, funções pós-midiáticas, cidade e mobilidade. Urbe - Revista Brasileira de Gestão Urbana (Brazilian Journal of Urban Management), Curitiba, v. 2, n. 2, p. 155-166, jul./dez. 2010.

LÉVY, Pierre. Cibercultura. Tradução de Carlos Irineu da Costa. São Paulo: Editora 34. 1999.

MINECRAFT. In: WIKIPÉDIA: a enciclopédia livre. Disponível em: <https://pt.wikipedia.org/wiki/Minecraft>. Acesso em: 15 abr. 2016.

SANTOS, Edméa. A cibercultura e a educação em tempos de mobilidade e redes sociais: conversando com os cotidianos. In: FONTOURA, Helena Amaral da; SILVA, Marco. Práticas pedagógicas, linguagem e mídias: desafios à pós-graduação em educação em suas múltiplas dimensões. Rio de Janeiro: ANPEd Nacional, 2011. p. 75-98. Disponível em: <http://www.fe.ufrj.br/anpedinha2011/ebook1.pdf>. Acesso em: 26 out. 2016.

SCHMITZ, John Robert. Ensino/aprendizagem das quatro habilidades linguísticas na escola pública: uma meta alcançável? In: LIMA, Diógenes Cândido de (Org.). Ensino e aprendizagem de língua inglesa: conversa com especialistas. São Paulo: Parábola Editorial, 2009. p. 13-20.

SQUIRE, Kurt. Video games and learning: teaching and participatory culture in the digital age. New York: Teachers College Press, 2011.

Este é um artigo de acesso aberto distribuído sob os termos da Licença CreativeCommons Atribuição Não Comercial-Compartilha Igual (CC BYNC- 4.0), que permite uso, distribuição e reprodução para fins não comerciais, com a citação dos autores e da fonte original e sob a mesma licença. 